Available online at www.banglajol.info

Bangladesh J. Sci. Ind. Res. 47(3), 297-302, 2012
BANGLADESH JOURNAL OF SCIENTIFIC AND INDUSTRIAL RESEARCH

E-mail: bjsir07@gmail.com

\title{
In vitro mass propagation of Plumbago zeylanica L., through direct organogenesis
}

\author{
A. K. M. S. Hassan*a, F. Haque ${ }^{c}$, M. A. A. Jahan ${ }^{c}$ and S. K. Roy ${ }^{b}$ \\ ${ }^{a}$ Department of Botany, Savar College, Savar, Dhaka-1340, ${ }^{b}$ Department of Botany, Jahangirnagar University, \\ Savar, Dhaka-1342, Bangladesh and ${ }^{c}$ Biological Research Division, BCSIR Laboratories, Dhaka-1205.
}

\begin{abstract}
An efficient protocol was developed for in vitro mass propagation of an important medicinal shrub, Plumbago zeylanica L., (Plumbaginaceae) through direct organogenesis using shoot tip and nodal explants. Best shoot induction was observed on MS basal medium supplemented with $0.5 \mathrm{mg} / 1 \mathrm{BAP}$, in which $86.4 \%$ of nodal explants responded to produce maximum number (12.4 \pm 0.66$)$ of shoots per culture. In vitro raised shoots rooted on half strength MS medium with $0.5 \mathrm{mg} / \mathrm{l}$ IAA. For acclimatization and transplantation, the plantlets in the rooted culture tubes were kept in normal room temperature for 7 days before transplanting in pots where plantlets were reared for three weeks. The survival rate of regenerated plantlets was $85 \%$.
\end{abstract}

Key words : Plumbago zeylanica, Medicinal plant, Organogenesis, Shoot proliferation, Mass propagation, Acclimatization

\section{Introduction}

Plumbago zeylanica L. commonly known as 'Chitra' belongs to the family - Plumbaginaceae, an undershrub with somewhat woody stem, strangling branches, thin ovate leaves, white flowers in elongate spikes and angled seed capsules (Fig.1a), grow in wastlands and graveyards in almost all areas of Bangladesh (Ghani, 2003). The roots are used extensively in China and other Asian countries for the treatment of cancer, rheumatoid arthritis, diarrhoea and extrem constipation (Rahman, 1988). Extract of the root is given internally or applied to the ostium uteri, causes abortion (Premakumari et al., 1977 and Bharghava,1984). The roots contain an alkaloid- plumbagin, a natural napthaquinone, possessing various pharmacological activities such as antimalarial (Didry et al., 1994), anticancer, cardiotonic, antifertility action, antibiotic and antineoplastic (Kirtikar and Basu, 1975; Modi, 1961; Krishnaswamy and Purushottamam, 1980; Pillai et al., 1981). The root paste is applied in order to open abscesses; a paste prepared with milk, vinegar or salt and water is used as an external application in leprosy and other skin disease of an obstinate character (Anonymous, 1989). Paste of equal proportion of root and bark is applied locally to haemorrhoids and in skin disease, whereas root bark decoction is taken orally two to three times daily to treat diarrhoea (Jaiswal, 2010). The root stimulates the secretion of sweat urine and bile and has a stimulant action on the nervous system. Coconut oil is processed with the root to a straw yellow colour and is used as a hair tonic, stimulating hair growth (Mallikadevi et al., 2008).

Propagation through seed is very difficult due to poor quality, lower germination rate and less seedling survivability under natural field conditions (Chaplot et al., 2005). In recent years, there has been an increased interest in in vitro culture techniques which offer a viable tool for mass multiplication and germplasm conservation of rare, endangered and threatened medicinal plants (Ajithkumar and Seeni 1998; Prakash et al. 1999). Commercial exploitation and elimination of natural habits consequent to urbanization has led to gradual extinction of several medicinal plants. Micropropagation is an effective approach to conserve such germplasm. In vitro propagation has proven as a potential technology for mass scale production of medicinal plant species (Hassan and Roy, 2005; Lui and Li, 2001; Martin 2002, 2003). It is important, therefore to develop an efficient micropropagation technique for Plumbago zeylanica $\mathrm{L}$. for rapidly disseminate superior clones. There have been few reports to date on in vitro mass propagation of Plumbago zeylanica L. using shoot tip and nodal explants (Mallikadevi et al., 2008; Sahoo and Debata, 1998; Seivakumar et al., 2001). Mallikadevi et al. (2008) reported that the in vitro 
regeneration of Plumbago zeylanica L., exhibited that the callus was initiated in the basal medium containing BAP, NAA, 2,4-D and IBA and the high amount (90\%) of organic calli was induced in the basal medium supplemented with 2.4-D alone at $2.0 \mathrm{mg} / 1$ and in the subculture the adventitious shoot formation was prominently higher (83\%) in the basal medium containing BAP and NAA at 3.5 and 0.3 $\mathrm{mg} / \mathrm{l}$ respectively and Sahoo and Debata (1998) reported that a rapid and highly effective method for plant micropropagation from vegetative shoot buds was established for this medicinal plant Plumbago zeylanica L.; multiple shoots were proliferated from nodal explants culture on MS basal medium supplemented with $0.25-1.0 \mathrm{mg} / \mathrm{Kn}$ or $0.25-1.0$ $\mathrm{mg} / \mathrm{l} \mathrm{BAP}$ and Seivakumar et al. (2001) also reported that rapid in vitro propagation using nodal explants cultured in MS basal medium supplimented with $10.0 \mathrm{mg} / \mathrm{l}$ ADS with $0.5 \mathrm{mg} / 1 \mathrm{IBA}$. The present study was therefore undertaken to develop a protocol for in vitro mass propagation of this important medicinal shrub through direct organogenesis using shoot tip and nodal explants.

\section{Materials and Methods}

Plumbago zeylanica L., grown at Medicinal Plants Garden of Bangladesh Agricultural University, Mymensingh was used as a source of explants. Shoot tip and nodal explants with a single axillary bud were used for this purpose. The explants were washed thoroughly under running tap water, pre-soaked in liquid detergent for about $30 \mathrm{~min}$, wiped with cotton
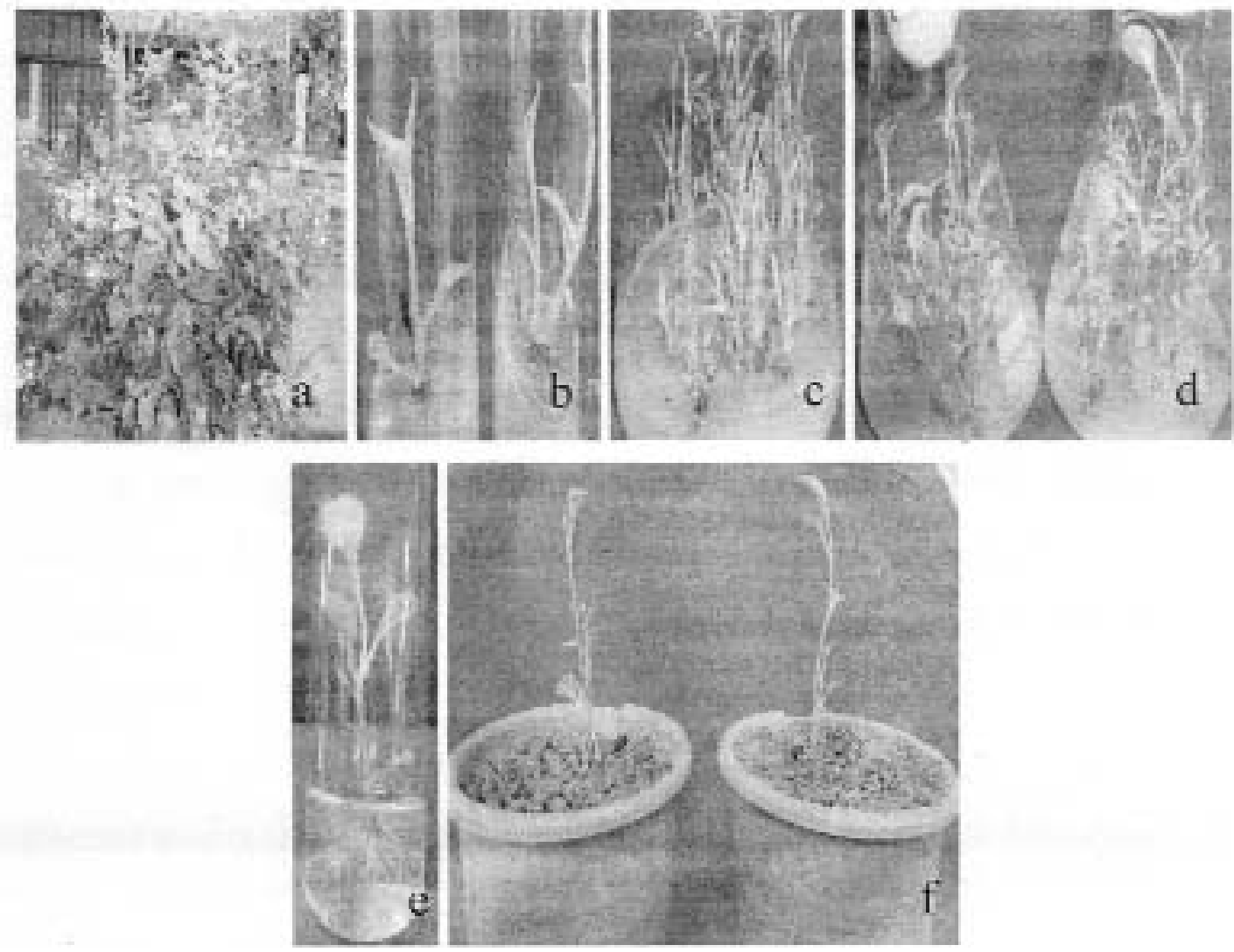

Fig 1: In vitro regeneration of Plumbago zeylanica L., from nodal explants.

(a) A mature plant from where explants were taken.

(b) Induction of shoots from nodal explants on MS $+0.5 \mathrm{mg} / \mathrm{l} \mathrm{BAP}$ in three weeks of culture.

(c) Development and multiplication of shoots from nodal explants on MS $+0.5 \mathrm{mg} / \mathrm{l} \mathrm{BAP}$ after six weeks of culture.

(d) Development and multiplication of shoots from nodal explants on MS $+0.5 \mathrm{mg} / \mathrm{l} \mathrm{BAP}$ after nine weeks of culture.

(e) Rooting of in vitro regenerated shoots cultured on half strength MS $+0.5 \mathrm{mg} / 1 \mathrm{IAA}$ in third weeks of culture.

(f) Acclimatized regenerated plants of two months old. 
and dipped in $70 \%(\mathrm{v} / \mathrm{v})$ ethanol for $1 \mathrm{~min}$. They were then surface-sterilized with $0.1 \%(\mathrm{w} / \mathrm{v})$ mercuric chloride for 5 min, followed by five times rinse with sterile distilled water under laminar air flow cabinet. The surface-sterilized explants were sized to $1-1.5 \mathrm{~cm}$ length containing a single node with an axillary bud or a shoot tip with an apical bud. The explants were placed vertically on the culture medium. The new shoots induced from the in vitro cultures were further used as an explants for adventitious shoot regeneration.

MS (Murashige and Skoog, 1962) basal medium was used for shoot proliferation and adventitious shoot regeneration and half strength MS was used for in vitro root induction. All media were supplemented with $30 \mathrm{~g} / 1$ sucrose, $7 \mathrm{~g} / 1$ agar (Difco) and dispensed into $15 \times 150 \mathrm{~mm}$ culture tubes and 250 $\mathrm{ml}$ conical flasks. The $\mathrm{pH}$ of the media was adjusted to 5.8 before autoclaving at $1.9 \mathrm{~kg} / \mathrm{cm}^{2}$ pressure at $121{ }^{\circ} \mathrm{C}$ for 20 min. The cultures were incubated for a $16 \mathrm{~h}$ photoperiod at $24 \pm 2{ }^{\circ} \mathrm{C}$ under $1200 \mathrm{lux} / \mathrm{m}^{2}$ fluorescent light.

Shoot proliferation from shoot tip and nodal explants was obtained in two separate sets of experiments. In the first experiment $0.5-2.0 \mathrm{mg} / \mathrm{l} \mathrm{BAP}$ and $0.5-2.0 \mathrm{mg} / \mathrm{l} \mathrm{Kn}$ were incorporated into MS media to select the best cytokinin for the response of shoot induction. In the second set, combination of BAP (0.5-2.0 mg/l) with NAA (0.1-0.5 mg/l) and BAP $(0.5-2.0 \mathrm{mg} / \mathrm{l})$ with IAA $(0.1-0.5 \mathrm{mg} / \mathrm{l})$ were assessed for shoot multiplication. Number of new shoot proliferation of each culture was recorded after every week of inoculation.

For in vitro rooting, individual shoots $(3-5 \mathrm{~cm})$ were excised from the proliferated shoot cultures and implanted onto half strength MS media with different concentrations and combinations of NAA, IBA and IAA.

The rooted plants were taken out from the culture tubes, washed to remove agar gel adhered to the roots and transplanted to plastic pots with soil and compost (1:1) for hardening. The plantlets were kept in a polychamber at $80 \%$ relative humidity, $32 \pm 2{ }^{\circ} \mathrm{C}$ temperatures for a $12 \mathrm{~h}$ photoperiod under $1500 \mathrm{lux} / \mathrm{m}^{2}$ sun light for acclimation. Established plants were transplanted in earthen pots under natural conditions and the survival rate was recorded.

\section{Results and Discussion}

Shoot tip and nodal explants of Plumbago zeylanica L. were cultured on MS media supplemented with various concentration of BAP alone and with NAA or IAA for multiple shoot regeneration. The explants were found to be swollen and they produced two to three shoots within three weeks after inoculation (Fig. 1b) on MS media containing BAP alone but the number of shoots increased up to $12.4 \pm 0.66$ when the explants were cultured in MS with $0.5 \mathrm{mg} / \mathrm{l}$ BAP (Table I, Fig. 1c). Both the explants responded in the same medium

Table I: Effect of growth regulators in MS on multiple shoot regeneration of Plumbago zeylanica L. shoot tips and nodal explants

\begin{tabular}{ccccccc}
\hline & Growth regulators (mg/l) & \multicolumn{2}{c}{ shoot tips } & \multicolumn{2}{c}{ nodal explants } \\
\hline BAP & NAA & IAA & $\begin{array}{c}\text { \% of explants } \\
\text { forming shoots }\end{array}$ & $\begin{array}{c}\text { Mean No. of } \\
\text { Shoot/explant }\end{array}$ & $\begin{array}{c}\text { \% of explants } \\
\text { forming shoots }\end{array}$ & $\begin{array}{c}\text { Mean No. of } \\
\text { Shoot/explant }\end{array}$ \\
\hline 0.5 & & & $74.2 \pm 2.58$ & $9.4 \pm 0.65$ & $86.4 \pm 1.70$ & $12.4 \pm 0.66$ \\
1.0 & & $63.4 \pm 1.57$ & $7.6 \pm 0.45$ & $71.4 \pm 2.38$ & $11.6 \pm 0.72$ \\
1.5 & & $57.6 \pm 2.16$ & $6.4 \pm 0.72$ & $67.6 \pm 2.16$ & $10.4 \pm 1.18$ \\
2.0 & 0.1 & & $34.8 \pm 2.58$ & $5.8 \pm 0.76$ & $33.6 \pm 1.84$ & $09.4 \pm 0.82$ \\
0.5 & 0.2 & & $61.4 \pm 2.87$ & $6.2 \pm 0.59$ & $68.6 \pm 1.70$ & $10.6 \pm 1.14$ \\
1.0 & 0.5 & & $42.6 \pm 0.87$ & $5.6 \pm 0.77$ & $43.6 \pm 0.51$ & $09.6 \pm 0.91$ \\
1.5 & 0.5 & & $28.2 \pm 1.66$ & $4.0 \pm 0.63$ & $41.2 \pm 2.47$ & $08.4 \pm 0.66$ \\
2.0 & & $22.2 \pm 1.96$ & $3.4 \pm 0.45$ & $32.2 \pm 0.66$ & $07.8 \pm 0.95$ \\
0.5 & & $48.8 \pm 1.77$ & $5.0 \pm 0.39$ & $56.8 \pm 2.14$ & $09.2 \pm 0.76$ \\
1.0 & & & $26.6 \pm 1.66$ & $4.2 \pm 0.65$ & $47.6 \pm 2.10$ & $08.2 \pm 0.51$ \\
1.5 & 0.2 & $21.0 \pm 1.14$ & $3.4 \pm 0.45$ & $32.6 \pm 1.63$ & $07.4 \pm 0.91$ \\
2.0 & & 0.5 & $16.2 \pm 0.86$ & $2.4 \pm 0.59$ & $18.4 \pm 0.93$ & $06.4 \pm 0.66$ \\
\hline
\end{tabular}

Results are mean $\pm \mathrm{SE}$ of three experiments with 15 replications. 
but highest numbers of micro shoots were observed to be induced from nodal explants (Fig.1d). Combinations of BAP with NAA or IAA were not found to be suitable than BAP alone for shoot induction (Table I) and combinations of $\mathrm{Kn}$ with NAA or IAA were also not found to be suitable for shoot induction (Data were not shown). Sahoo and Debata (1998) reported that a rapid and highly effective method for plant micropropagation from vegetative shoot buds was established for this medicinal plant Plumbago zeylanica L. ; multiple shoots were proliferated from nodal explants culture on MS basal medium supplemented with $0.25-1.0 \mathrm{mg} / 1$ $\mathrm{Kn}$ or $0.25-1.0 \mathrm{mg} / \mathrm{l}$ BAP. A similar phenomenon was observed in Plumbago zeylanica L. by other researchers (Gbadamosi and Egunyomi, 2010; Mallikadevi et al., 2008; Selvakumar et al., 2001; Rout et al., 1999; Verma et al., 2002).

$86.2 \%$ regenerated shoots rooted (Fig.1e) when cultured individually on root induction medium consisted of halfstrength MS medium with $0.5 \mathrm{mg} / 1$ IAA (Table II). Use of auxins singly or in combination for rooting was also reported by different authors (Bhadra et al., 2009; Gopalakrishnan et al., 2009; Hassan and Khatun, 2010; Kumar and Bhavanandan, 1988; Sivakumar and Krishnamurthy 2000; Yogananth and Basu, 2009).

Table II: Effect of auxin(s) on root induction in regenerated shoots of Plumbago zeylanica L., on half strength MS

\begin{tabular}{|c|c|c|c|c|}
\hline \multicolumn{3}{|c|}{ Growth regulators $(\mathrm{mg} / \mathrm{l})$} & \multirow{2}{*}{$\begin{array}{c}\% \text { of shoots pro- } \\
\text { ducing roots }\end{array}$} & \multirow{2}{*}{$\begin{array}{c}\text { No. of } \\
\text { roots/shoot }\end{array}$} \\
\hline IAA & IBA & IAA & & \\
\hline 0.5 & & & $86.2 \pm 0.71$ & $14.8 \pm 0.76$ \\
\hline 0.75 & & & $67.2 \pm 1.53$ & $11.8 \pm 0.65$ \\
\hline 1.0 & & & $63.2 \pm 1.46$ & $09.2 \pm 0.76$ \\
\hline 1.5 & & & $61.0 \pm 0.10$ & $07.6 \pm 0.72$ \\
\hline & 0.5 & & $77.8 \pm 1.85$ & $06.2 \pm 0.76$ \\
\hline & 0.75 & & $64.2 \pm 1.53$ & $05.0 \pm 0.63$ \\
\hline & 1.0 & & $62.0 \pm 0.71$ & $04.8 \pm 0.59$ \\
\hline & 1.5 & & $59.4 \pm 1.08$ & $03.2 \pm 0.71$ \\
\hline & & 0.5 & $65.2 \pm 1.16$ & $05.8 \pm 0.65$ \\
\hline & & 0.75 & $61.4 \pm 0.75$ & $04.6 \pm 0.96$ \\
\hline & & 1.0 & $62.6 \pm 0.93$ & $03.6 \pm 0.72$ \\
\hline & & 1.5 & $56.2 \pm 1.85$ & $02.2 \pm 0.76$ \\
\hline
\end{tabular}

Data were recorded after four weeks of culture. Results are mean $\pm \mathrm{SE}$ of 15 replications.
After four weeks the rooted shoots were transferred to pots. None of the plantlets were survived when directly transferred from rooting medium to the pot under natural conditions. About 85 percent of the transplanted plants of Plumbago zeylanica L., survived if the plants in the rooting culture tubes were kept in normal room temperature for seven days before transplantation in pots and reared for three weeks. The plantlets were reared under semi-controlled temperature $\left(30 \pm 2^{\circ} \mathrm{C}\right)$ and light (1500 lux) in a chamber with 80 percent humidity. During this period of acclimation shoots elongated, leaves expanded and turned deep green and healthier (Fig.1f).

After three weeks, plants were transferred to an open place and gradually acclimatized to outdoor conditions, where 85 percent plants were survived. The technique described here appears to be readily adaptable for large scale clonal propagation and plantation for sustainable use.

\section{Acknowledgement}

The authors are indebted to the Professor Dr. S. M. Imamul Huq, Chairman, BCSIR, Dhaka. Grateful acknowledgement is also due to Dr. Rahima Khatun, Director, Institute of Fuel Research and Development, BCSIR, Dhaka for their kind permission, sincere suggestions and moral support during research work.

\section{References}

Ajithkumar D and Seeni S (1998). Rapid clonal multiplication through in vitro axillary shoot proliferation of Aegle marmelos (L) Corr., A Medicinal Tree. Plant Cell Rep. 17 : 422-426.

Anonymous (1989). The Wealth of India: Raw Materials. CSIR, New Delhi, India.Vol. VIII: Ph-Re, pp 162-164.

Bhadra SK, Akhter T and Hossain MM (2009). In vitro micropropagation of Plumbago indica L. through induction of direct and indirect organogenesis. Plant Tissue Cult. and Biotech. 19 (2): 169-175.

Bharghava SK (1984). Effects of plumbagin on reproductive function of male dog. Ind. J. Exp. Biol. 22: 153-156.

Chaplot BB, Vadawale AV, Jhala JM and Barve DM (2005). Clonal propagation of value added medicinal plant- 
safed moosli (Chlorophytum borivilianum), In: J.N. Govil and V.K. Singh (Eds.). Recent Progress in Medicinal plants, Studium Press, LLC: Texas, USA, pp. 383-388.

Didry N, Dubrevil L and Pinkas M (1994). Activity of anthraquinonic and naphthoquinonic compounds on oral bacteria. Die Pharmazie. 49: 681-683.

Gbadamosi IT and Egunyomi A (2010) Micropropagation of Plumbago zeylanica L. (Plumbaginaceae) in Ibadan, Southwestern, Nigeria. Journal of Medicinal Plants Research. 4(4): 293-297.

Ghani A (2003). Medicinal Plants of Bangladesh with Chemical Constituents and Uses. 2nd Ed. (Asiatic military press, Dhaka, 1000) pp 350-351.

Gopalakrishnan M, Janarthananm B, Sai G.L and Sekar T (2009). Plant regeneration from leaf explants of Plumbago rosea L. Plant Tissue Cult. and Biotech. 19 (1): 79-87.

Hassan AKMS and Khatun R (2010). Regeneration of Ficus glomerata Roxb., using Shoot tips and Nodal explants. Bangladesh Journal of Botany. 39(1): 47-50.

Hassan AKM.S. and Roy SK (2005). Micropropagation of Gloriosa superba L. through high frequency shoot proliferation. Plant Tissue Cult. and Biotech. 15 (1): 6774.

Kiritkar KR and Basu BD (1975). Indian Medicinal Plants, Indological Oriental Publishers, Delhi, India.

Krishnaswamy M and Purushottamam KK (1980). Plumbagin, a study of its anticancer, antibacterial and antifungal properties. Ind. J. Exp. Biol. 18: 876-877.

Kumar KS and Bhavanandan KV (1988). Micropropagation of Plumbago rosea Linn. Plant Cell Tissue and Organ Culture. 15(3): 275-278.

Jaiswal V (2010). Culture of Ethnobotany of Jaintia Tribal Community of Maghalaya, Northeast, India. 9(1): 3844.

Lui Z and Li Z (2001). Micropropagation of Camptotheca acuminata Decaisne. from axillary buds, shoot tips and seed embryos in tissue culture system. In Vitro Cell Dev. Biol. Plant. 37: 84-88.

Martin KP (2002). Rapid propagation of Holostema adakodien Schult. a rare medicinal plant, through axillary bud multiplication and indirect organogenesis. Plant Cell Rep. 21: 112-117

Mallikadevi T, Senthilkumar P and Paulsamy S (2008). In vitro regeneration of the medicinal plant, Plumbago zeylanica $\mathrm{L}$. with reference to a unique population in maruthamalai, the western ghats, India. Plant Tissue Cult. and Biotech. 18 (2): 173-179.

Martin KP (2003). Plant regeneration through somatic embryogenesis on Holostema ada-kodien Schult. a rare medicinal plant. Plant Cell Tiss. Orga. Cult. 72: 79-82.

Modi J (1961). Textbook of Medicinal Jurisprudence and Toxicology, Pripati. Pvt. Ltd. Bombay, India.

Murashige T and Skoog F. (1962). A revised medium for rapid growth and bioassays with tobacco tissue culture. Physiol. Plant. 15 : 473-479.

Pillai NG.K, Menon TV, Pillai G.B, Rajasekharan S and Nair CRR (1981). Effect of plumbagin in charmakeela (common warts) a case report. J. Res. Ayur. Sidha 2: $12-126$.

Prakash E, Khan SSV, Reddy PSSP and Rao KR (1999) Regeneration of plants from seed-derived callus of Hybanthus enneaspermus L. Muell., a rare ethnobotanical herb. Plant Cell Rep. 18: 873-878.

Premakumari P, Rathinam K and Santhakumari G (1977). Antifertility activity of plumbagin. Ind. Med. Res. 65: 829-838.

Rahman A (1988). Studied in Natural Products Chemistry, Eisevier, Amsterdam, The Netherlands.

Rout GR, Saxena C, Das P and Samantaray S (1999). Rapid clonal propagation of Plumbago zeylanica Linn. Plant Growth Regulation. 28(1): 1-4.

Sahoo S and Debata BK (1998). Micropropagation of 
Plumbago zeylanica Linn. Journal of Herbs, Spices \& Medicinal Plants. 5(4): 87-93.

Selvakumar V, Anbudurai RR and Balakumar T (2001). In vitro propagation of the medicinal plant Plumbago zeylanica L. through nodal explants. In Vitro Cell Dev. Biol. Plant. 37(2): 280-284.

Sivakumar G and Krishnamurthy KV (2000). Micropropagation of Gloriosa superba L.- an endangered species of Asia and Africa. Current Science. 78(1): $30-32$.
Verma P.C., Singh D., Rahman L. Gupta M.M. and Banerjee S (2002). In vitro studies in Plumbago zeylanica: rapid micropropagation and establishment of higher plumbagin yielding hairy root culture. Journal of Plant Physiology. 159(5): 547-552.

Yogananth N and Basu MJ (2009). TLC method for the determination of plumbagin in hairy root culture of Plumbago rosea L. Global Journal of Biotechnology \& Biochemistry. 4(1): 66-69.

Received : 27 September 2010; Revised : 28 September 2011; Accepted : 24 October 2011. 